\title{
Review
}

\section{Adam Smith: Systematic philosopher and public thinker}

\author{
Eric Schliesser \\ Oxford: Oxford University Press, 2017, xxiv + 407 pp., \\ ISBN 978-0190690120
}

Contemporary Political Theory (2019) 18, S49-S51. https://doi.org/10.1057/s41296018-0232-5; published online 5 June 2018

If one thing has puzzled Adam Smith's interpreters since his death, it has been the systematicity of his thought. As evidenced by the continuing prominence of the famous 'Das Adam Smith Problem' - the supposed incompatibility of principles espoused in Wealth of Nations [WN] and The Theory of Moral Sentiments [TMS]readers of Smith have often struggled to articulate the core commitments and coherence of Smith's system. Yet relatively little ink has been spilled on Smith's philosophy of systems as such, including his philosophy of social science. Less ink still has been spent on the connection between how or whether Smith's philosophy of systems informs what might be called his public thought, that is, his pragmatic political, economic, and social concerns.

In this new and truly comprehensive study of Smith's primary works, Eric Schliesser seeks to fill in these gaps by expounding Smith's multidimensional treatment of 'systems' and the 'system-inspired public spirit' (p. 6) he takes Smith to develop deliberately across his corpus. Schliesser goes well beyond any expected engagement with secondary literature or the intellectual context of Smith's work to conceptually situate his arguments and Smith's texts. As such, the book is of immediate interest to any political theorist or philosopher working on Adam Smith or on the long eighteenth century. Beyond its specific interest to specialists, Schliesser's book should also be of value to those interested in the future of liberalism as an ideology. Borrowing Hayek's phrase, Schliesser identifies himself as rearticulating some of the "“old truths" of liberalism,' whose survival he now thinks 'cannot be presupposed even in its historical heartland' (pp. 11, 16). Although the book is intensely exegetical, Schilesser thus also intends it to contribute to the ongoing contemporary debate about the value of liberalism.

Schliesser's book is divided into three main parts, which tackle Smith's various systems and his concerns about their public effect(s). The first two broadly deal with Smith's 'systematic philosophy,' first primarily from the perspective of the individual (Part I) and then from the perspective of society (Part II). Part III is

(C) 2018 Macmillan Publishers Ltd., part of Springer Nature. 1470-8914 Contemporary Political Theory Vol. 18, S1, S49-S51 www.palgrave.com/journals 
considerably shorter than the other two but focuses on Smith as 'public thinker,' especially his concern with the public effects of religion and philosophy. In Part I, Schliesser explores Smith's theory of human nature and what he calls 'Smithian social explanation' (p. 33) - the approach to giving a causal account of socially useful phenomena that emphasizes their historically contingent and path-dependent nature alongside their invisibility to agents immersed in them. (In Part II, Schliesser tries to distinguish this kind of social explanation from the more familiar doctrine of unintended consequences.) Central to this discussion is Schliesser's innovative analysis of Smith's account of the passions, which divides them up into the 'proto,' 'natural,' 'intellectual,' and 'derived' (p. 49), according to whether they consist of preconceptions about the world (proto), are innate (natural, intellectual), or require society (derived). He ends this section on individual moral psychology with a discussion of the importance of superstitious belief, including a nuanced treatment of the 'piacular' feeling that drives moral agents to seek atonement (pp. 121-134).

Part II is devoted to Smith's social philosophy, including his political theory and political economy. Throughout (but especially Chapters 11 and 13), it integrates Smith's philosophy of science into his social theory, frequently relying on selections from the less explored Essays on Philosophical Subjects. While Schliesser joins many left-leaning Smith interpreters in suggesting Smith's prescribed economic and political institutions are biased toward the working poor in this section, he does so for very different reasons: namely, as evidence of Smith's consequentialism. Given the pervasive bias toward the interests of economic and political elites in market economies, Schliesser 'speculates' that Smith proposes policies to benefit the poor to moderate this distribution of power (p. 208). Social institutions that promote equity are good on Schliesser's reading, then, not because they are beneficial for the greatest number and not necessarily because they satisfy requirements of justice, but rather because they ensure moderation. Part II also includes an extended analysis (Chapter 10) of the only three mentions of the infamous invisible hand in Smith's corpus. In contrast to Smithian social explanations and to the conventional reading, Schliesser argues that invisible hand processes can be foreseen by informed observers, even if they may not be obvious to particular agents engaged in them. If this interpretation might suggest Schliesser reads Smith as too eager or optimistic about the possibility for social reform, he tempers it with an in-depth treatment of Smith's skepticism, including his wariness about applying mathematics to economics and even some of the natural sciences.

Part III, though the briefest, is the portion of the book that deals most explicitly with the second part of its subtitle. There Schliesser uses Smith's views on religion (returning to some of his arguments about the critical influence of superstition from Part I) and philosophy as such (especially as Smith articulates in correspondence and vis-à-vis his friendship with Hume) as examples of his fundamentally public or pragmatic thought. Although Smith recognizes the pervasiveness and importance of superstitious thinking, Schliesser claims, he nevertheless recognizes some of the 
deleterious effects of religion and thus promotes freedom and moderation in its practice. The book ends fittingly with Schliesser highlighting Smith's insistence on the importance of philosophy in shaping public belief, alongside a qualified suggestion about his esotericism.

Although this book is not without its imperfections, there is still much in it to recommend it to those interested in learning more about Smith's political theory, exploring the philosophical underpinnings of liberal political economy, or even those interested in the interplay between political theory and political practice. Schliesser recasts Smith as a fundamentally philosophic and political thinker in interesting ways that have often been overlooked or downplayed in past scholarship. Chief among this book's laudable contributions are its real engagement with Smith's philosophy as it is developed throughout the Essays on Philosophical Subject. Schliesser analyzes not only the increasingly popular essay, 'Principles that Direct Philosophic Inquiry,' but also less familiar essays on imagination and the external senses to develop Smith's epistemology, philosophy of science, and even metaphysics much more substantially than has previously been done. More relevantly for readers of this journal, one of Schliesser's controversial claims- that Smith has a capacious understanding of liberty that includes not only freedom of contract but also the freedom made possible by the rule of law-demonstrates the central role of politics in both morality and economics according to Smith. As for its shortcomings, I sometimes found the conversational tone difficult to follow and the parenthetical remarks or 'interludes' (e.g. p. 15) distracting, though they are largely the product of Schliesser's immersion in the scholarship. I was also unpersuaded by his claim that Smith is an 'innate ideas theorist' (p. 20), which primarily relies on 'proto-passions' that seem to entail a belief about the existence of the external world but are not entirely well defined or distinguished from intuitions in Chapter 3. Nevertheless, Smith specialists and political theorists alike will find this rich volume rewards those who devote the time necessary to engage with it.

Michelle Schwarze University of Wisconsin-Madison, Madison, WI 53706, USA mschwarze@wisc.edu 